\title{
Comparison of Different Techniques to Design of Filter
}

\author{
Shushank Dogra \\ Department of Electronics and communication \\ Amritsar college of Engeering and Technology, \\ Amritsar, India
}

\author{
Narinder Sharma \\ Department of Electronics and Communication \\ Amritsar college of Engeering and Technology, \\ Amritsar, India
}

\begin{abstract}
For the design of filters complex calculations are required. Mathematically, by substituting the values of parameters according to any of the filter used in any of the methods from window method, frequency sampling method or optimal method we can get the values of filter coefficients $h(n)$. There are different window methods like Kaiser window,rectangular window,triangular window ect.Kaiser window method has been chosen preferably because of the presence of ripple factor $(\beta)$.Here, I have design Band pass FIR and low pass filter using artificial neural network which gives optimum result i.e. the difference between the actual and desired output is minimum and also shows the comparision between low pass and bandpass filter or comparison of different techniques used to design the filter.
\end{abstract}

\section{INTRODUCTION}

The basic function of digital filter is to eliminate the noise and to extract the signal of interest from other signals. A digital filter filter is a basic device used in digital signal processing. There are several techniques available to design the digital filters. But generally while designing a digital filter, first an analog filter is designed and then it is converted into the corresponding digital filter. With the technological evolution, great advances have been made on design techniques for various digital filters. A filter is essentially a system or network that selectively changes the wave shape amplitude frequency and or phase - frequency characteristics of a signal in a desired manner. A digital filter is a mathematical algorithm implemented in hardware and/or software that operates on a digital input signal to produce a digital output signal for the purpose of achieving a filtering objective. (Wade et al., 1990) described filters are synthesized by cascading elements from a library of computationally simple and some case very computationally efficient, primitive filter. A simplified block diagram of a real-time digital filter, with analog input and output signals is given in Figure 1.1

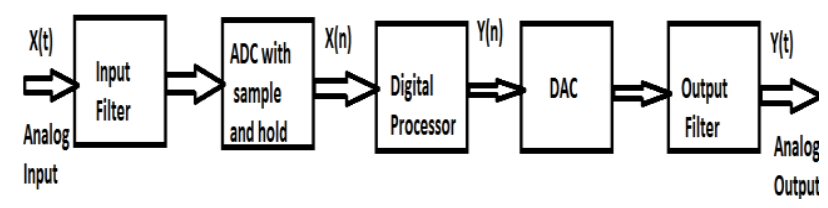

Fig 1: Block diagram of digital filter

\section{A.Analog Filters}

This is necessary because generally digital filters are designed using analog filters. Some parameters related to analog filters:

- Pass band: It passes certain range of frequencies. In the pass band, attenuation is 0 .

- Stop band: It suppresses certain range of frequencies. In the stop band, attenuation is infinity.
- Cut-off frequency: This is frequency which separates pass band and stop band.

Types of analog filters:

The different types of analog filters are as follows:

- Low pass filter (L.P.F): It passes the frequency from 0 upto some designated frequency, called as cut-off frequency. After cut-off frequency, it will not allow any signal to pass through it.

- High pass filter (H.P.F): It passes the frequency above some designated frequency called as cut-off frequency. If input signal frequency is less than the cutoff frequency, then this signal is not allowed to pass through it.

- Band Pass Filter (B.P.F): It allows the frequencies between two designated cut-off frequencies.

- Band Stop Filter (B.S.F): It attenuates all frequencies between two designated cut-off frequencies, while it passes all other frequencies.

- All Pass Filter: It passes all the frequencies. But by using this filter the phase of input signal can be modified.

Types of digital filters: FIR and IIR filters[Ifeachor] Digital filters are broadly divided into two classes, namely infinite Impulse Response (IIR) and Finite Impulse Response (FIR) filters. Either type of filter, in its basic form, can be represented by its impulse response sequence, $\mathrm{h}(\mathrm{k})(\mathrm{k}=0,1,2$ .....), as in

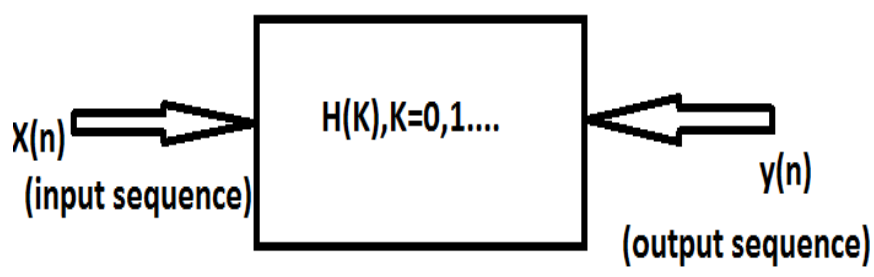

Fig.2.A conceptual representation of a digital filter

The equation for IIR is

$$
Y(n)=\sum_{k=0}^{\infty} \mathrm{h}(\mathrm{k}) \mathrm{x}(\mathrm{n}-\mathrm{k})
$$

The equation for FIR is

$$
Y(n)=\sum_{k=0}^{n-1} \mathrm{~h}(\mathrm{~K}) \mathrm{x}(\mathrm{n}-\mathrm{k})
$$




\section{Merits of FIR filters over IIR filters}

- FIR filters have an exactly linear phase responses where the phase responses of IIR filters are non linear.

- FIR are realized nonrecursively, that is by direct evaluation are always stable. The stability of IIR filters cannot always be guaranteed.

- The coefficient quantization error is much less severe in FIR than in IIR.

\section{STEPS OF FIR FILTER DESIGN}

The design of a digital filter involves five steps as shown in figure:

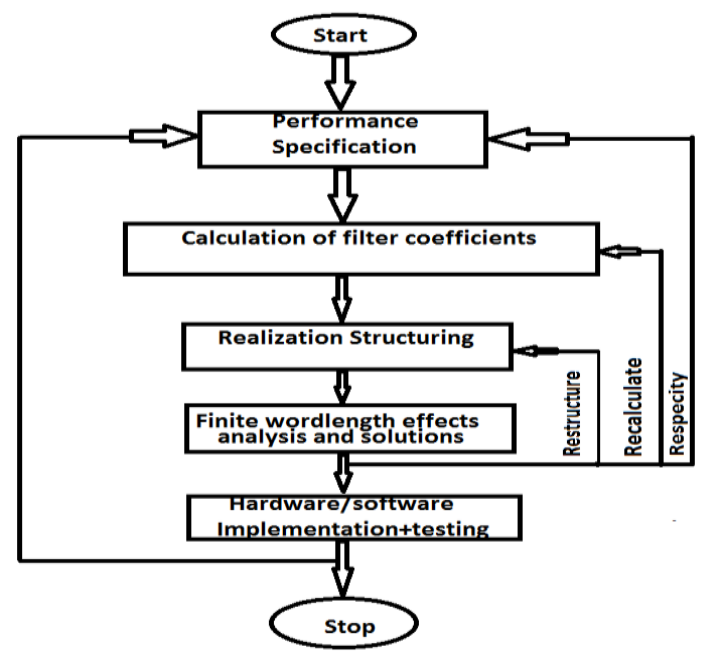

Fig.3.summary of design stages of filter

The criteria is a linear phase response in frequency domain called phase response (Jin et al., 2006) as shown in Fig.. Finally, because there is a tradeoff between filter complexity and implementation feasibility, complexity and implementation feasibility, complexity is a performance criteria. Ideal filter characteristics are practically unrealizable.

\section{A.METHODS TO DESIGN FIR FILTER}

We have many methods to design FIR filter that are:-

- Fourier series method

- Frequency Sampling method

- Window method

The most of these design techniques suffer from some kinds of drawback, Some of them could not give optimal design in any sense, some is lacking of generality, some need long computing time, and so on (Bagachi and Mitra, 1996). Kaiser window method has been used because of the presence of ripple parameter beta.

\section{TYPES OF WINDOW FUNCTIONS}

There are many windows proposed that approximate the desired characteristics. The basic window functions are listed below:

\section{Rectangular Window}

The rectangular window (sometimes known as the boxcar or Dirichlet window) is the simplest window, equivalent to replacing all but $N$ values of a data sequence by zeros, making it appear as though the waveform suddenly turns on and off:

$$
\mathrm{W}(\mathrm{n})=1
$$

The M point rectangular window, which corresponds to direct truncation of the Fourier series, has the weighted function

$$
\begin{aligned}
& \mathrm{W}_{\mathrm{r}}(\mathrm{n})=1, \quad \text { for- }(\mathrm{M}-1) / 2 \leq \mathrm{n} \leq(\mathrm{M}-1) / 2 \\
& 0 \text {, otherwise }
\end{aligned}
$$

\section{Triangular window}

Triangular windows are given by:

$$
w(n)=1-\left|\frac{n-\frac{N-1}{2}}{\frac{L}{2}}\right|,
$$

where $\mathbf{L}$ can be $\mathrm{N}, \mathrm{N}+1$, or $\mathrm{N}-1$. The latter is also known as Bartlett window. All three definitions converge at large $N$.

The triangular window is the 2 nd order $B$-spline window and can be seen as the convolution of two half-sized rectangular windows, giving it twice the width of the regular windows.

\section{Bartlett Window}

By tapering the rectangular window sequence linearly from the middle to the ends, we then obtain the $\mathrm{M}$ point triangular window given by

$$
\begin{array}{rlrl}
\mathrm{W}_{\mathrm{T}}(\mathrm{n})=2 \mathrm{n} /(\mathrm{M}-1) & & \text { for } 0 \leq \mathrm{n} \leq(\mathrm{M}-1) / 2 \\
& 2-2 \mathrm{n} /(\mathrm{M}-1) & & \text { for }(\mathrm{M}-1) / 2<\mathrm{n} \leq(\mathrm{M}-1) \\
& 0, & & \text { otherwise }
\end{array}
$$

This window is also called Barlett window.

\section{Raised Cosine Windows}

Another class of windows is raised cosine windows that, compared with the triangular window, are smoother at the ends, but closer to one at the middle. The smoother taper at the ends should reduce the side-lobe levels, while the broader middle section reduces distortion of the desired pulse response bound $\mathrm{n}=0$ (Garimella, 2008). To reduce the side-lobe level further, we can consider an even more gradual taper at the ends of the window sequence by using the raised cosine sequence. The various windows in this category are:

\section{Hanning window}

The Hann window named after Julius von Hann and also known as the Hanning (for being similar in name and form to the Hamming window), von Hann and the raised cosine window is defined by

$\mathrm{W}_{\mathrm{c}}(\mathrm{n})=0.5-0.5 \cos \left(\frac{2 \pi n}{M}-1\right)$, for $0 \leq n \leq(M-$ 1)

$$
0
$$

\section{otherwise}

\section{Hamming Window}

Hamming window is given by

$$
\begin{aligned}
& W h(n)=0.54-0.46 \cos \left(\frac{2 \pi n}{M}-1\right), \quad \text { for } 0 \leq n \\
& \leq(M-1)
\end{aligned}
$$




\section{Blackman window}

Blackman window is given by

$\mathrm{W}_{\mathrm{b}}(\mathrm{n})=$

$$
0.42-0.5 \cos \left(\frac{2 \pi n}{M-1}\right)+0.08 \cos \left(\frac{4 \pi n}{M-1}\right), \text { for } 0 \leq n \leq(M-1)
$$

0

otherwise

The difference between these windows are shown below:

\section{TABLE.1 Comparison of Windows}

\begin{tabular}{|l|l|l|l|}
\hline $\begin{array}{l}\text { Window } \\
\text { Type }\end{array}$ & $\begin{array}{l}\text { Peak Side } \\
\text { lobe } \\
\text { amplitude } \\
\text { (relative) }\end{array}$ & $\begin{array}{l}\text { Approximate } \\
\text { Width of } \\
\text { main lobe }\end{array}$ & $\begin{array}{l}\text { Peak } \\
\text { Approximation } \\
\text { Error 20log } \delta \\
(\mathrm{dB})\end{array}$ \\
\hline Rectangular & -13 & $4 \pi / \mathrm{M}+1$ & 21 \\
\hline Barlett & -25 & $8 \pi / \mathrm{M}$ & -25 \\
\hline Hanning & -31 & $8 \pi / \mathrm{M}$ & -44 \\
\hline Hamming & -41 & $4 \pi / \mathrm{M}$ & -53 \\
\hline Blackmann & -57 & $12 \pi / \mathrm{M}$ & -74 \\
& & & \\
\hline
\end{tabular}

\section{KAISER WIDOW}

Kaiser determined empirically that the value of $\beta$ need to achieve a specified value of $\mathrm{A}$ is given by

$$
\beta= \begin{cases}0.1102(\mathrm{~A}-8.7) & \text { for } \mathrm{A}>50 \\ 0.5842(\mathrm{~A}-21)^{0.4}+0.07886(\mathrm{~A}-21) & \text { for } 21 \leq \mathrm{A} \leq 5 \\ 0.0 & \text { for } \mathrm{A}<21\end{cases}
$$

Recall that the case $\beta=0$ is the rectangular window for which $A=21$. Further more, to achieve prescribed values of $A$ and df, M must satisfy equations

$$
M= \begin{cases}\frac{A-8}{14.36 d f}+1 & \text { for } A>21 \\ (0.922 / d f)+1 & \text { for } A \leq 21\end{cases}
$$

Finite Impulse response filters (Öner and paper., 1999) are preferred for their stable and linear phase characteristics. But due to long impulse response of FIR filters there will be more hardware complexity.

\section{ARTIFICIAL NEURAL NETWORK}

An Artificial Neural Network is an information processing paradigm inspired by the way the densely inter-connected, parallel structure of the mammalian brain process information. ANN have successfully applied to a number of problems including the identification and control of dynamical systems, communications networks, coordination of robotics handeye movements.It is also referred to as a neuromorphic system, follows connectionist architecture, and parallel distributed processing. Artificial Neural Networks are collections of mathematical models that emulate some of the observed properties of biological nervous system. The key element of the ANN is the novel structure of the information processing systems.

Some other advanrtages of ANN are as under:

\section{Adaptive learning \\ 2. Self-Organisation \\ 3. Real Time Operation}

\section{A.Multilayer Perceptron Networks[3],[4]}

Multilayer Perceptron Networks [3-4]form a class of feed forward neural networks. They are not a single layer network but consist of an input layer, arbitrary number of hidden layers and an output layer as shown in figure 1.5.Here input is fed to each of the input layer neurons. The outputs of the input layer feed into each of next layer neurons and so on, forming a layered structure having one input layer, one output layer and L-2 hidden layers in an L layer network.The following diagram illustrates a perceptron network with three Layers:

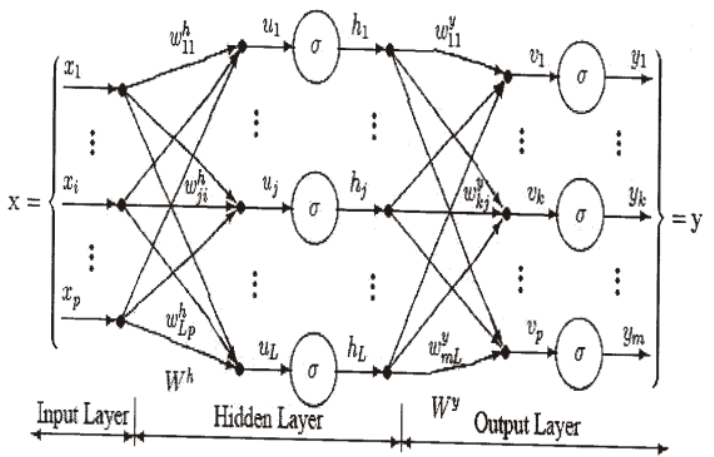

Fig.2: Multilayer Perceptron

\section{B. Formulation of Problem}

The design of digital filter means basically finding the values of filter coefficients so that given filter specification are achieved the window based design method are exclusively used for calculating there coefficient. We have used Kaiser window for this purpose. The Kaiser window function goes somehow in overcoming the incorporating a ripple control parameter, ANNs have been used for the design of Bandpass filter with Passband ripple, stop band attenuation, passband frequency $\mathrm{F}$ 1, passband frequency F2, sampling frequency and for lowpass with Passband, transition width, passband ripple, stop band attenuation, sampling frequency as input parameters. The network has been trained in such a manner so that the error comes minimum, means there may be very less difference in the results comes from actual calculations that has been come from matlab and the output comes from trained artificial neural network.

\section{C.OBJECTIVE:}

The objective of the present work are divided into the following sections.

(1)To prepare the data sheet using different values of filter parameter achieve the filter coefficient.

(2)Choosing ANN a Band-pass FIR filter has been designed such that its coefficient match with coefficients obtained with window method. 


\section{COMPARISON OF RESULTS OF LOWPASS FILTER WITH BANDPASS FILTER}

Filter coefficient are calculated and works is carried out using approximately 30 such values of all the above parameters to calculate the filter coefficients. The range of different parameters of lowpass and bandpass has been taken which are:

TABLE.2.Comparison of lowpass with bandpass filter

\begin{tabular}{|l|l|}
\hline LOWPASS FILTER & BANDPASS FILTER \\
PARAMETER & PARAMETER \\
\hline SBT: (10.1040-9.3860) & Ap: $(0.7-1.3) \mathrm{db}$ \\
TW: $(50-100)$ & As: $(40-55) \mathrm{db}$ \\
PBR: $(0.1-0.2)$ & F1: $(7000-11000) \mathrm{hz}$ \\
N: (3-10) & F2: $(17000-21000) \mathrm{hz}$ \\
PBF:(150- 180) & Fs:(47000-52000) hz \\
\hline
\end{tabular}

Using this data set the Artificial Neural Network has been trained and can be use to calculate filter coefficients for input parameters in this range.Now, ANN is use to design the band pass and lowpass FIR filter.There is very less difference in the ann results and the calculated results.

INPUT PARAMETER OF LOWPASS- Transition width $=50 \mathrm{~Hz}$, SamplingFrequency $=1 \mathrm{KHz}$,Passbandripple $=0.1 \mathrm{~d}$ b,

Filterlength $=3$,Passband $=150 \mathrm{~Hz}$,stopbandattenuation $=10.1040$

TABLE.3.Comparison of Kaiser window method with ANN

\begin{tabular}{|l|c|c|}
\hline $\mathrm{h}(\mathrm{n})$ & $\begin{array}{l}\text { Kaiser Window } \\
\text { Method }\end{array}$ & $\begin{array}{l}\text { ArtificialNeural } \\
\text { Network }\end{array}$ \\
\hline $\mathrm{h}(0)$ & 0.2885 & 0.2805 \\
\hline $\mathrm{h}(1)$ & 0.4231 & 0.4206 \\
\hline $\mathrm{h}(2)$ & 0.2885 & 0.2667 \\
\hline $\mathrm{h}(3)$ & 0.0000 & 0.0004 \\
\hline $\mathrm{h}(4)$ & 0.0000 & 0.0200 \\
\hline $\mathrm{h}(5)$ & 0.0000 & 0.0068 \\
\hline $\mathrm{h}(6)$ & 0.0000 & 0.0182 \\
\hline $\mathrm{h}(7)$ & 0.0000 & 0.0191 \\
\hline $\mathrm{h}(8)$ & 0.0000 & 0.0031 \\
\hline $\mathrm{h}(9)$ & 0.0000 & 0.0075 \\
\hline $\mathrm{h}(10)$ & 0.0000 & 0.0092 \\
\hline $\mathrm{h}(11)$ & 0.0000 & 0.0047 \\
\hline $\mathrm{h}(12)$ & 0.0000 & 0.0000 \\
\hline
\end{tabular}

INPUT PARAMETER OF BANDPASS- Passband ripple $=0.729$, Stopband attenuation $=41.502$ PassbandfrequencyF $1=$ 9815, PassbandfrequencyF2=18234 ,Sampling frequency $=49661$. Filter Length $=17$

TABLE.4. Error values obtained from difference between Kaiser window and ANN.

\begin{tabular}{|c|c|c|c|}
\hline $\mathrm{h}(\mathrm{n})$ & $\begin{array}{c}\text { Kaiser } \\
\text { Window } \\
\text { Method }\end{array}$ & $\begin{array}{c}\text { Artificial } \\
\text { Neural } \\
\text { Network }\end{array}$ & $\begin{array}{c}\text { Error } \\
\text { Values }\end{array}$ \\
\hline $\mathrm{h}(0)$ & 0.0001 & -0.0014 & 0.0015 \\
\hline $\mathrm{h}(1)$ & 0.0047 & 0.0058 & -0.0011 \\
\hline $\mathrm{h}(2)$ & 0.0109 & 0.0100 & 0.0009 \\
\hline $\mathrm{h}(3)$ & -0.0204 & -0.0209 & 0.0005 \\
\hline $\mathrm{h}(4)$ & -0.0108 & -0.0101 & -0.0007 \\
\hline $\mathrm{h}(5)$ & 0.0329 & 0.0331 & -0.0002 \\
\hline $\mathrm{h}(6)$ & -0.0019 & -0.0015 & -0.0004 \\
\hline $\mathrm{h}(7)$ & -0.0306 & -0.0306 & -0.0000 \\
\hline $\mathrm{h}(8)$ & 0.0076 & 0.0075 & 0.0001 \\
\hline $\mathrm{h}(9)$ & 0.0001 & 0.0003 & -0.0002 \\
\hline $\mathrm{h}(10)$ & 0.0188 & 0.0185 & 0.0003 \\
\hline $\mathrm{h}(11)$ & 0.0286 & 0.0284 & 0.0002 \\
\hline $\mathrm{h}(12)$ & -0.0906 & -0.0895 & -0.0011 \\
\hline $\mathrm{h}(13)$ & -0.0166 & -0.0175 & 0.0009 \\
\hline $\mathrm{h}(14)$ & 0.1686 & 0.1695 & -0.0009 \\
\hline $\mathrm{h}(15)$ & -0.0560 & -0.0547 & -0.0013 \\
\hline $\mathrm{h}(16)$ & -0.1980 & -0.1982 & 0.0002 \\
\hline $\mathrm{h}(17)$ & 0.1482 & 0.1483 & -0.0001 \\
\hline
\end{tabular}

\section{CONCLUSION}

The present work has illustrated the need of Artificial Neural Network for the design of Filters and also shows the comparision of all other methods to design the filter.

The following conclusions are drawn from this research work:

- Artificial Neural Network is better and easy method of Design of FIR Filter.

- Using Fourier series, Frequency sampling or Window methods the filter can be design but for each unknown parameter the filter coefficients have to calculated. In comparison with ANN, the trained network can calculate the filter Coefficient for unknown parameter in that specified range.

\section{REFERENCES}

[1] V. Aggarwal, J. O. Wesley and M. O Una., (2006) "Filter approximation using Explicit Time and Frequency Remain specification". Proceeding, of the Annual Symposium on Artificial Intelligence, 2006, Seattle, Washington, pp. 174-165.

[2] A. M. Cristian and H. Guinther, (2007) "Architecture Optimization of a Finite Impulse Response Filter using togglebased power estimation", International conference, on intelligent and Advance systems, 2007, pp. 12701273.

[3] A. Fizelow., P. Brites., A. Ochoa., H. Mertuns., E. Fernandez, and Garcia-Martinez R. (2007) "Finding Optimal Neural Network Architecture using Genetic Algorithms," Proceeding of the advances in computer and Engineering, 2007, pp. 15-24.

[4] D. Bhattacharya and A. Antoniou, (1996) "Real Time Design of FIR Filters of Feedback Neural Network", Vol. 3, 1996, pp. 1070-1078

[5] D. A. Yasur and R. Teresa., (2007) "LUT-based Power Macro modeling Technique for DSP architectures", Proceeding of the IEEE, Centro de Electronica Industrial, Spain, August, 2007, pp. 1416-1419. 
[6] K.B. Englihart, B.S. Hudgins, M. Stevenson and P.A. Parker, (1994) "Myoelectric Signal Classification using a Finite Impulse Response Neural Network". Technical Report, The university of New Brunswork, Canada, June, 1994, pp. 803-820.

[7] Z. Fan and P. Mars, (1997) "Access flow control scheme for ATM networks using neural-network-based traffic prediction". Proceeding for IEEE, Vol. 144, Dec. 5, October 1997, pp. 708-714.

[8] G. Rama Marthy. (2008) "Finite Impulse Response FIR filter Model of Synapses: Associated Neural Network", Proceeding of the Fourth Annual IEEE International Confidences on Natural Computation, 2008, pp. 33043309.

[9] G. Zichao and U. E. Robert., (1992) "Using Genetic Algorithms to select input for Neural Network". Proceeding of the IEEE International conference, May, 1992, pp. 87-95.

[10] K.J. Hintz. and J.J.Spofford , (1990) "Evoling Neural Network" Proceedings of the IEEE Transactions on Communication and Intelligence, May 1990, pp. 333338.
[11] S. Haykins, (2003), "Neural Networks - A comprehensive foundation", Prentice - Hall of India Private Limited, NewDelhi 2003.

[12] I. Ioan., R. Corina and I. Arpad., (2004) "The optimization of feedforward", proceedings of the international and information - ICTAMI 2004, Thessaloniki, Greece.

[13] I F. Emmonual C. and J. Barriel W. (2001) "Digital Signal Processing," A Practical Approch," Person Education (Singapore) Ltd., 2001, Second Edition.

[14] J. Y. Dar. and C. F. Kun., (2007) "Least square Design of FIR Filters based on a compacted Feedback Neural Network", Proceeding of the IEEE Transaction on Circuits and systems, vol. 54 issue 5, May, 2007, pp. 427-431. "Magnetization, M", not just "M". If including units in the label, present them within parentheses. Do not label axes only with units. In the example, write "Magnetization (A/m)" or "Magnetization $\{\mathrm{A}[\mathrm{m}(1)]\}$ ", not just " $\mathrm{A} / \mathrm{m}$ ". Do not label axes with a ratio of quantities and units. For example, write "Temperature (K)", not "Temperature/K". 